\title{
Surgical versus nonsurgical treatment for lumbar degenerative spondylolisthesis.
}

\author{
James N Weinstein \\ Dartmouth Medical School \\ Jon D Lurie \\ Dartmouth Medical School \\ Tor D Tosteson \\ Dartmouth Medical School \\ Brett Hanscom \\ Dartmouth Medical School \\ Follow this and additional works at: https://jdc.jefferson.edu/rothman_institute \\ ina N A Tosteson \\ vartmort ith the dirthpereflics Commons \\ Let us know how access to this document benefits you
}

\section{See next page for additional authors}

\section{Recommended Citation}

Weinstein, James N; Lurie, Jon D; Tosteson, Tor D; Hanscom, Brett; Tosteson, Anna N A; Blood, Emily A; Birkmeyer, Nancy J O; Hilibrand, Alan; Herkowitz, Harry; Cammisa, Frank P; Albert, Todd J; Emery, Sanford E; Lenke, Lawrence G; Abdu, William A; Longley, Michael; Errico, Thomas J; and $\mathrm{Hu}$, Serena S, "Surgical versus nonsurgical treatment for lumbar degenerative spondylolisthesis." (2007). Rothman Institute Faculty Papers. Paper 12.

https://jdc.jefferson.edu/rothman_institute/12

This Article is brought to you for free and open access by the Jefferson Digital Commons. The Jefferson Digital Commons is a service of Thomas Jefferson University's Center for Teaching and Learning (CTL). The Commons is a showcase for Jefferson books and journals, peer-reviewed scholarly publications, unique historical collections from the University archives, and teaching tools. The Jefferson Digital Commons allows researchers and interested readers anywhere in the world to learn about and keep up to date with Jefferson scholarship. This article has been accepted for inclusion in Rothman Institute Faculty Papers by an authorized administrator of the Jefferson Digital Commons. For more information, please contact: JeffersonDigitalCommons@jefferson.edu. 


\section{Authors}

James N Weinstein, Jon D Lurie, Tor D Tosteson, Brett Hanscom, Anna N A Tosteson, Emily A Blood, Nancy J O Birkmeyer, Alan Hilibrand, Harry Herkowitz, Frank P Cammisa, Todd J Albert, Sanford E Emery, Lawrence G Lenke, William A Abdu, Michael Longley, Thomas J Errico, and Serena S Hu 
ORIGINAL ARTICLE

\section{Surgical versus Nonsurgical Treatment for Lumbar Degenerative Spondylolisthesis}

\author{
James N. Weinstein, D.O., Jon D. Lurie, M.D., Tor D. Tosteson, Sc.D., \\ Brett Hanscom, M.S., Anna N.A. Tosteson, Sc.D., Emily A. Blood, M.S., \\ Nancy J.O. Birkmeyer, Ph.D., Alan S. Hilibrand, M.D., Harry Herkowitz, M.D., \\ Frank P. Cammisa, M.D., Todd J. Albert, M.D., Sanford E. Emery, M.D., M.B.A., \\ Lawrence G. Lenke, M.D., William A. Abdu, M.D., Michael Longley, M.D., \\ Thomas J. Errico, M.D., and Serena S. Hu, M.D.*
}

ABSTRACT

BACKGROUND

Management of degenerative spondylolisthesis with spinal stenosis is controversial. Surgery is widely used, but its effectiveness in comparison with that of nonsurgical treatment has not been demonstrated in controlled trials.

\section{METHODS}

Surgical candidates from 13 centers in 11 U.S. states who had at least 12 weeks of symptoms and image-confirmed degenerative spondylolisthesis were offered enrollment in a randomized cohort or an observational cohort. Treatment was standard decompressive laminectomy (with or without fusion) or usual nonsurgical care. The primary outcome measures were the Medical Outcomes Study 36-Item ShortForm General Health Survey (SF-36) bodily pain and physical function scores (100point scales, with higher scores indicating less severe symptoms) and the modified Oswestry Disability Index (100-point scale, with lower scores indicating less severe symptoms) at 6 weeks, 3 months, 6 months, 1 year, and 2 years.

RESULTS

We enrolled 304 patients in the randomized cohort and 303 in the observational cohort. The baseline characteristics of the two cohorts were similar. The one-year crossover rates were high in the randomized cohort (approximately $40 \%$ in each direction) but moderate in the observational cohort (17\% crossover to surgery and $3 \%$ crossover to nonsurgical care). The intention-to-treat analysis for the randomized cohort showed no statistically significant effects for the primary outcomes. The as-treated analysis for both cohorts combined showed a significant advantage for surgery at 3 months that increased at 1 year and diminished only slightly at 2 years. The treatment effects at 2 years were 18.1 for bodily pain ( $95 \%$ confidence interval [CI], 14.5 to 21.7), 18.3 for physical function (95\% CI, 14.6 to 21.9), and -16.7 for the Oswestry Disability Index (95\% CI, -19.5 to -13.9). There was little evidence of harm from either treatment.

\section{CONCLUSIONS}

In nonrandomized as-treated comparisons with careful control for potentially confounding baseline factors, patients with degenerative spondylolisthesis and spinal stenosis treated surgically showed substantially greater improvement in pain and function during a period of 2 years than patients treated nonsurgically. (ClinicalTrials. gov number, NCT00000409.)
From the Departments of Orthopaedics (J.N.W., B.H., E.A.B., W.A.A.), Medicine (J.D.L., A.N.A.T.), and Community and Family Medicine (J.N.W., T.D.T., A.N.A.T.), Dartmouth Medical School, Lebanon, $\mathrm{NH}$; the University of Michigan, Ann Arbor (N.J.O.B.); the Rothman Institute at Thomas Jefferson University, Philadelphia (A.S.H., T.J.A.); William H. Beaumont Hospital, Royal Oak, MI (H.H.); the Hospital for Special Surgery, New York (F.P.C.); the University Hospitals of Cleveland and Case Western Reserve University, Cleveland (S.E.E.); Washington University, St. Louis (L.G.L.); the Nebraska Foundation for Spinal Research, Omaha (M.L.); the Hospital for Joint Diseases, New York (T.J.E.); and the University of California at San Francisco, San Francisco (S.S.H.). Address reprint requests to Dr. Weinstein atSPORT@dartmouth.edu.

*Other investigators participating in the Spine Patient Outcomes Research Trial (SPORT) are listed in the Appendix.

N Engl J Med 2007;356:2257-70.

Copyright (c) 2007 Massachusetts Medical Society. 
$\mathrm{D}$

EGENERATIVE SPONDYLOLISTHESIS IS the slipping forward of one lumbar vertebra on another with an intact neural arch. It rarely occurs before the age of 50 years, and it disproportionately affects women, particularly black women, with a male:female ratio of approximately 1:6. ${ }^{1}$ Slippage most commonly occurs at the L4-L5 level and rarely exceeds $30 \%$ of vertebral width. ${ }^{1}$ Degenerative spondylolisthesis is generally asymptomatic, but it can be associated with symptomatic spinal stenosis. ${ }^{1}$

Spinal stenosis, the most common reason for lumbar surgery in adults over the age of 65 , is a narrowing of the spinal canal with encroachment on the neural structures by surrounding bone and soft tissue. Patients typically present with neurogenic claudication - pain in the buttocks or legs with walking or standing that resolves with sitting or lumbar flexion. However, anatomical spinal stenosis is frequently detected by imaging studies in asymptomatic patients; thus, clinical correlation between symptoms and imaging is critical. ${ }^{2}$

Two studies have compared surgery with nonsurgical treatment for spinal stenosis, but both of these studies included patients with and those without degenerative spondylolisthesis. ${ }^{3-5}$ Several studies have compared surgical techniques in cohorts with degenerative spondylolisthesis; however, these studies had small samples with limited geographic participation and lacked nonsurgical controls and validated outcome measures. ${ }^{6-8}$ The optimal treatment strategy for symptomatic degenerative spondylolisthesis remains unclear.

The Spine Patient Outcomes Research Trial (SPORT) was designed to compare the effectiveness of surgical and nonsurgical treatment among participants with confirmed diagnoses of intervertebral disk herniation, ${ }^{9,10}$ spinal stenosis, and degenerative spondylolisthesis. ${ }^{11}$ Here we report the 2-year outcomes of patients with degenerative spondylolisthesis.

\section{METHODS}

\section{STUDY DESIGN}

The SPORT was conducted in 11 states at 13 medical centers in the United States that have multidisciplinary spine practices. The SPORT included both a randomized cohort and a concurrent observational cohort with identical selection criteria and outcomes assessment. ${ }^{12}$ The standardized protocol was approved by human subjects committees at each participating institution, and an independent data and safety monitoring board monitored the results of the trial. The principal investigator had full access to all the data in the study and takes responsibility for the accuracy and integrity of the data analysis. Additional background information has been published previously. ${ }^{9-11,13}$

\section{PATIENT POPULATION}

All patients had neurogenic claudication or radicular leg pain with associated neurologic signs, spinal stenosis shown on cross-sectional imaging, and degenerative spondylolisthesis shown on lateral radiographs obtained with the patient in a standing position. The patients had had persistent symptoms for at least 12 weeks and had been confirmed as surgical candidates by their physicians. Patients with adjacent levels of stenosis were eligible; patients with spondylolysis and isthmic spondylolisthesis were not. The nature of nonsurgical care before enrollment was not prespecified but included physical therapy in $68 \%$ of patients, epidural injections in 55\%, chiropractic treatment in 25\%, antiinflammatory agents in $63 \%$, and opioid analgesic agents in $30 \%$.

Research nurses at each site identified potential participants and verified their eligibility. The patients were offered enrollment in either cohort and gave written informed consent after viewing videotapes explaining the expected benefits, risks, and uncertainties of the treatments. ${ }^{14,15}$ Participants in the randomized cohort received computergenerated random treatment assignments blocked according to center; those in the observational cohort chose their treatment with their physician. Enrollment began in March 2000 and ended in February 2005.

\section{STUDY INTERVENTIONS}

The protocol surgery consisted of a standard posterior decompressive laminectomy with or without bilateral single-level fusion (iliac crest bone grafting with or without posterior pedicle-screw instrumentation). ${ }^{11}$ The nonsurgical protocol was usual care, recommended to include at least active physical therapy, education or counseling including instructions for exercising at home, and nonsteroidal antiinflammatory agents if tolerated. ${ }^{11,13}$

\section{STUDY MEASURES}

The primary end points were the Medical Outcomes Study 36-Item Short-Form General Health Survey 
(SF-36) bodily pain and physical function scores ${ }^{16-19}$ and the Oswestry Disability Index (American Academy of Orthopaedic Surgeons/Modems version) ${ }^{20}$ measured at 6 weeks and at 3, 6, 12, and 24 months after enrollment. Secondary outcomes included patient-reported improvement, satisfaction with current symptoms and care, ${ }^{21}$ the Stenosis Bothersomeness Index, ${ }^{22,23}$ and the Low Back Pain Bothersomeness Scale. ${ }^{3}$ The SF-36 scores range from 0 to 100, with higher scores indicating less severe symptoms; the Oswestry Disability Index ranges from 0 to 100 , with lower scores indicating less severe symptoms; the Stenosis Bothersomeness Index ranges from 0 to 24, with lower scores indicating less severe symptoms; and the Low Back Pain Bothersomeness Scale ranges from 0 to 6 , with lower scores indicating less severe symptoms.

\section{STATISTICAL ANALYSIS}

A sample size of 150 patients in each treatment group for the randomized cohort was determined as sufficient on the basis of a two-sided t-test with a power of 0.85 to detect a 10-point difference in the SF-36 bodily pain and physical function scores or a similar effect size in the Oswestry Disability Index. The sample size allowed for up to $20 \%$ of the data to be missing but did not account for any specific levels of nonadherence.

Initial analyses compared baseline characteristics of the patients between the randomized cohort and the observational cohort and between the treatment groups of the combined randomized cohort and the observational cohort. The extent of missing data and the percentage of patients undergoing surgery were calculated for each scheduled follow-up. Baseline predictors of time until surgical treatment in both cohorts (including treatment crossovers) were determined by a stepwise proportional-hazards regression model with an inclusion criterion of $\mathrm{P}<0.1$ to enter and $\mathrm{P}>0.05$ to exit. Predictors of missing follow-up visits at 1 year were determined by stepwise logistic regression with entry and exit criteria of $\mathrm{P}<0.1$ and $\mathrm{P}>0.05$, respectively.

Primary analyses compared surgical and nonsurgical treatments using changes from baseline at each follow-up time for SF-36 bodily pain and physical function and for the Oswestry Disability Index. The randomized cohort was initially analyzed on an intention-to-treat basis. However, because of the extent of crossover, subsequent analy- ses combined the randomized cohort and the observational cohort and were based on treatments actually received. In these as-treated analyses, the treatment indicator was a time-varying covariate, allowing for variable times to surgery. Before the time of surgery, all changes from baseline were included in the estimates of the nonsurgical treatment effect. After surgery, subsequent changes in outcomes were assigned to the surgical group with follow-up measured from the date of surgery. The randomized cohort and the observational cohort were each analyzed to produce separate as-treated estimates of treatment effect. These results were compared with the use of a Wald test to simultaneously test all follow-up visit times for differences in estimated treatment effects between the randomized and observational groups. ${ }^{24}$ Subsequent analyses combined the two cohorts.

To adjust for potential confounding effects, baseline variables associated with missing data or treatment received were included as covariates in longitudinal regression models. ${ }^{24} \mathrm{~A}$ random effect was specified to account for the correlation between the repeated measurements of individual patients. Computations were performed with the use of SAS software (PROC MIXED for continuous data with normal random effects and PROC GENMOD for binary and non-normal secondary outcomes). Statistical significance was defined as $\mathrm{P}<0.05$ on the basis of a two-sided hypothesis test (SAS software, version 9.1). Data for these analyses were collected through October 3, 2006.

\section{RESULTS}

Overall, 607 of 892 eligible participants were enrolled in the SPORT (304 in the randomized cohort and 303 in the observational cohort). A total of 601 patients (99\%) completed at least one follow-up visit and were included in the analysis; between $83 \%$ and $95 \%$ of enrollees supplied data at each follow-up visit (Fig. 1).

In the randomized cohort, 159 patients were assigned to surgery and 145 to nonsurgical treatment. Of those assigned to surgery, $57 \%$ underwent surgery by 1 year and 64\% by 2 years. In the group assigned to nonsurgical care, $44 \%$ underwent surgery by 1 year and $49 \%$ by 2 years. In the observational cohort, 173 patients initially chose surgery and 130 initially chose nonsurgical care. Of those initially choosing surgery, $97 \%$ underwent surgery by 1 year, and one additional pa- 


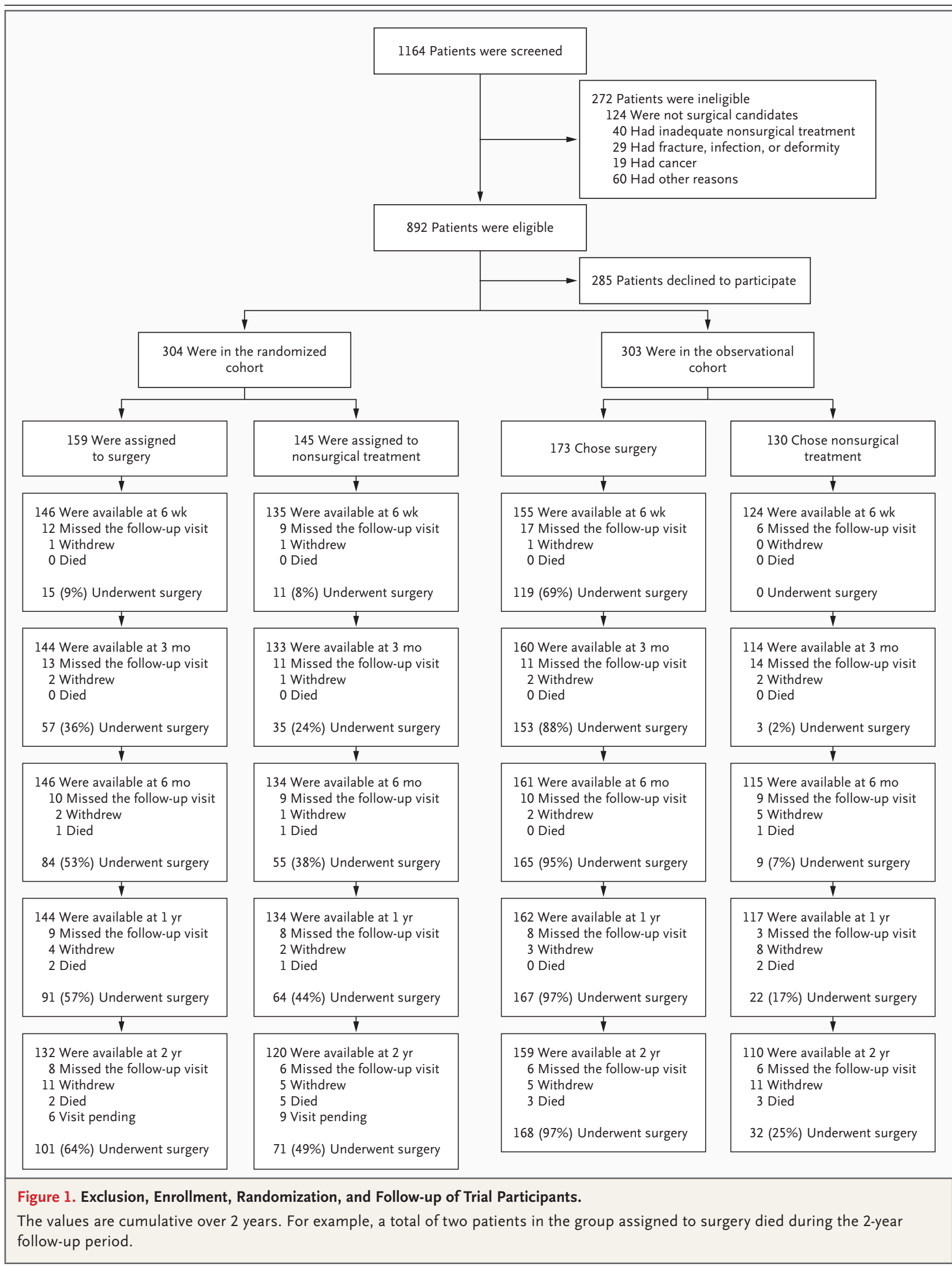

The New England Journal of Medicine

Downloaded from nejm.org at THOMAS JEFFERSON UNIVERSITY on June 19, 2012. For personal use only. No other uses without permission. Copyright @ 2007 Massachusetts Medical Society. All rights reserved. 
tient underwent surgery between 1 and 2 years from the time of enrollment. Of those initially choosing nonsurgical treatment, $17 \%$ underwent surgery by 1 year and 25\% by 2 years. In both cohorts combined, 372 patients underwent surgery within the first 2 years and 235 received only nonsurgical treatment.

\section{PATIENT CHARACTERISTICS}

Table 1 shows the baseline characteristics and clinical findings of participants in the randomized and the observational cohorts. The cohorts were remarkably similar; however, patients in the observational cohort had more L4-L5 involvement, less involvement of L3-L4, and less lateral recess stenosis.

Summary statistics for the combined cohorts are also shown in Table 1 according to treatment received; the mean age was 66 years. Eighty-five percent of patients had neurogenic claudication, and $77 \%$ had associated dermatomal pain radiation. Most of the degenerative slips and associated stenoses were at L4-L5. On imaging, stenosis was graded as severe in $60 \%$ of patients, and 35\% had multiple levels of stenosis.

At baseline, patients in the group undergoing surgery from the combined randomized and observational cohorts were younger and more likely to be receiving compensation (e.g., workers' compensation or social security) than those receiving nonsurgical treatment. They had worse pain, function, disability, and symptoms than patients in the nonsurgical group. Patients in the surgery group were more dissatisfied with their symptoms and at enrollment more often rated their symptoms as worsening. This observation highlights the need to control for baseline differences in the adjusted models. The final model controlled for the following covariates, selected as described in the Methods section: age, sex, work status, depression, osteoporosis, joint problems, duration of current symptoms, reflex deficit, number of moderate or severe stenotic levels, baseline score (for the SF-36, the Oswestry Disability Index, and the Stenosis Bothersomeness Index), and the center where the patient was treated. SF-36 and the Oswestry Disability Index scores were also adjusted for the baseline Stenosis Bothersomeness Index score.

Lateral radiographs obtained with the patient in a neutral standing position were available for independent review for 169 patients. The percentage of slip as measured by the method of Mor- gan and King ${ }^{25}$ ranged from 1 to $37 \%$ (median, $15 \%$; interquartile range, 10 to $21 \%$ ). Eighty-six percent of patients had grade 1 slip and 14\% had grade 2 .

\section{NONSURGICAL TREATMENTS}

Nonsurgical treatments used during the SPORT included physical therapy (42\%), epidural steroid injections $(45 \%)$, nonsteroidal antiinflammatory drugs (51\%), and opioids (34\%). Nonsurgical treatments were similar in the randomized cohort and the observational cohort, though more patients in the randomized cohort reported visits to a surgeon $(44 \%$ vs. $34 \%, P=0.04)$, receiving injections ( $49 \%$ vs. $37 \%, \mathrm{P}=0.02)$, and narcotics use $(40 \%$ vs. $26 \%, P=0.007)$.

\section{SURGICAL TREATMENT AND COMPLICATIONS}

The median surgical time was 199 minutes, with a mean blood loss of $589 \mathrm{ml}$ (Table 2). There were no significant differences between the cohorts in rates of intraoperative blood replacement, but there was a difference in the postoperative transfusion rates $(16 \%$ in the randomized cohort vs. $26 \%$ in the observational cohort, $\mathrm{P}=0.04)$. The most common surgical complication was dural tear (10\%). The 2 -year reoperation rate was $12 \%$.

\section{MAIN TREATMENT EFFECTS}

The intention-to-treat analysis of the randomized cohort showed no statistically significant effects for the primary outcomes, on the basis of a global hypothesis test for differences in mean changes from baseline between the treatment groups including all time periods. Treatment effects at 2 years were 1.5 for SF-36 bodily pain (95\% confidence interval [CI], -4.2 to $7.3 ; \mathrm{P}=0.52), 1.9$ for physical function ( $95 \% \mathrm{CI},-3.7$ to $7.5 ; \mathrm{P}=0.71$ ), and 2.2 for the Oswestry Disability Index $(95 \% \mathrm{CI}$, -2.3 to $6.8 ; \mathrm{P}=0.68$ ).

As-treated effects for the combined cohorts were statistically significant in favor of surgery for all primary and secondary outcomes (Table 3 and Fig. 2). Treatment effects were stable for 2 years and were significant for all time periods, with treatment effects at 2 years of 18.1 for SF-36 bodily pain (95\% CI, 14.5 to 21.7), 18.3 for physical function (95\% CI, 14.6 to 21.9), and -16.7 for the Oswestry Disability Index (95\% CI, -19.5 to -13.9 ). The results of the intention-to-treat and the astreated analyses of the randomized and the observational cohorts are compared in Figure 2. The as-treated treatment effects at 2 years were nearly 


\begin{tabular}{|c|c|c|c|c|c|c|}
\hline Characteristic & $\begin{array}{c}\text { Randomized } \\
\text { Cohort } \\
(\mathrm{N}=301)\end{array}$ & $\begin{array}{l}\text { Observational } \\
\text { Cohort } \\
(\mathrm{N}=300)\end{array}$ & $\begin{array}{c}\mathbf{P} \\
\text { Value }\end{array}$ & $\begin{array}{l}\text { Surgical } \\
\text { Treatment } \\
(\mathrm{N}=368) \dagger\end{array}$ & $\begin{array}{l}\text { Nonsurgical } \\
\text { Treatment } \\
(\mathrm{N}=233)+\bar{i}\end{array}$ & $\begin{array}{c}P \\
\text { Value }\end{array}$ \\
\hline Age $-y r$ & $66.0 \pm 10.0$ & $66.1 \pm 10.6$ & 0.86 & $64.7 \pm 10.1$ & $68.2 \pm 10.3$ & $<0.001$ \\
\hline Female sex — no. (\%) & $200(66)$ & $212(71)$ & 0.30 & $255(69)$ & $157(67)$ & 0.69 \\
\hline \multicolumn{7}{|l|}{ Race or ethnic group - no. $(\%) \ddagger$} \\
\hline Non-Hispanic & $292(97)$ & $295(98)$ & 0.42 & $359(98)$ & $228(98)$ & 0.97 \\
\hline White & $259(86)$ & $247(82)$ & 0.26 & $316(86)$ & $190(82)$ & 0.19 \\
\hline Black & $29(10)$ & $32(11)$ & 0.78 & $30(8)$ & $31(13)$ & 0.06 \\
\hline Any college education - no. (\%) & $201(67)$ & $199(66)$ & 0.98 & $247(67)$ & $153(66)$ & 0.78 \\
\hline Married — no. (\%) & $198(66)$ & $198(66)$ & 0.98 & $249(68)$ & $147(63)$ & 0.29 \\
\hline Work status — no. (\%) & & & 0.42 & & & 0.96 \\
\hline Working full- or part-time & $116(39)$ & $102(34)$ & & $133(36)$ & $85(36)$ & \\
\hline Disabled & $21(7)$ & $30(10)$ & & $33(9)$ & $18(8)$ & \\
\hline Retired & $129(43)$ & $128(43)$ & & $156(42)$ & $101(43)$ & \\
\hline Other & $35(12)$ & $40(13)$ & & $46(12)$ & $29(12)$ & \\
\hline Compensation - no. (\%)』 & $21(7)$ & $20(7)$ & 0.99 & $34(9)$ & $7(3)$ & 0.005 \\
\hline Body-mass index $q$ & $29.1 \pm 5.7$ & $29.2 \pm 6.7$ & 0.91 & $29.4 \pm 6.5$ & $28.8 \pm 5.7$ & 0.22 \\
\hline Current smoker — no. (\%) & $23(8)$ & $28(9)$ & 0.55 & $34(9)$ & $17(7)$ & 0.49 \\
\hline \multicolumn{7}{|l|}{ Coexisting conditions - no. (\%) } \\
\hline Hypertension & $141(47)$ & $134(45)$ & 0.65 & $164(45)$ & $111(48)$ & 0.51 \\
\hline Diabetes & $39(13)$ & $41(14)$ & 0.89 & $48(13)$ & $32(14)$ & 0.90 \\
\hline Osteoporosis & $33(11)$ & $36(12)$ & 0.79 & $40(11)$ & $29(12)$ & 0.65 \\
\hline Heart problem & $61(20)$ & $61(20)$ & 0.94 & $65(18)$ & $57(24)$ & 0.055 \\
\hline Stomach problem & $64(21)$ & $69(23)$ & 0.68 & $79(21)$ & $54(23)$ & 0.70 \\
\hline Bowel or intestinal problem & $17(6)$ & $26(9)$ & 0.20 & $30(8)$ & $13(6)$ & 0.30 \\
\hline Depression & $56(19)$ & $42(14)$ & 0.16 & $63(17)$ & $35(15)$ & 0.57 \\
\hline Joint problem & $175(58)$ & $169(56)$ & 0.72 & $202(55)$ & $142(61)$ & 0.17 \\
\hline Other\| & $121(40)$ & $113(38)$ & 0.58 & $146(40)$ & $88(38)$ & 0.70 \\
\hline Symptom duration $>6$ mo - no. (\%) & $185(61)$ & $176(59)$ & 0.54 & $227(62)$ & $134(58)$ & 0.35 \\
\hline \multicolumn{7}{|l|}{ SF-36 scores*** } \\
\hline Bodily pain & $30.7 \pm 16.4$ & $31.7 \pm 17.5$ & 0.44 & $29.2 \pm 16.8$ & $34.4 \pm 16.7$ & $<0.001$ \\
\hline Physical function & $34.4 \pm 21.5$ & $34.3 \pm 23.3$ & 0.98 & $30.5 \pm 20.5$ & $40.3 \pm 23.9$ & $<0.001$ \\
\hline Mental component summary & $49.9 \pm 11.9$ & $50.5 \pm 11.2$ & 0.53 & $49.5 \pm 11.6$ & $51.3 \pm 11.3$ & 0.06 \\
\hline Oswestry Disability Index†'† & $41.8 \pm 16.5$ & $41.3 \pm 19.1$ & 0.72 & $45.0 \pm 16.6$ & $36.2 \pm 18.5$ & $<0.001$ \\
\hline Stenosis Frequency Indextr & $14.2 \pm 5.5$ & $13.8 \pm 5.7$ & 0.36 & $14.8 \pm 5.5$ & $12.6 \pm 5.4$ & $<0.001$ \\
\hline Stenosis Bothersomeness Index $\mathbb{\int} \int$ & $14.8 \pm 5.6$ & $14.6 \pm 5.6$ & 0.79 & $15.6 \pm 5.5$ & $13.3 \pm 5.4$ & $<0.001$ \\
\hline Low Back Pain Bothersomeness Scale $q \rrbracket$ & $4.3 \pm 1.8$ & $4.3 \pm 1.8$ & 0.99 & $4.4 \pm 1.8$ & $4.0 \pm 1.9$ & 0.01 \\
\hline Very dissatisfied with symptoms — no. (\%) & $203(67)$ & $213(71)$ & 0.39 & $287(78)$ & $129(55)$ & $<0.001$ \\
\hline Self-assessment of health trend - no. (\%) \|\| & & & 0.73 & & & $<0.001$ \\
\hline Problem getting better & $17(6)$ & $21(7)$ & & $17(5)$ & $21(9)$ & \\
\hline Problem staying about the same & $100(33)$ & $94(31)$ & & $89(24)$ & $105(45)$ & \\
\hline Problem getting worse & $179(59)$ & $182(61)$ & & $258(70)$ & $103(44)$ & \\
\hline Treatment preference at baseline - no. (\%) & & & $<0.001$ & & & $<0.001$ \\
\hline Definitely prefer nonsurgical treatment & $44(15)$ & $83(28)$ & & $32(9)$ & $95(41)$ & \\
\hline Probably prefer nonsurgical treatment & $71(24)$ & $37(12)$ & & $40(11)$ & $68(29)$ & \\
\hline Not sure & $117(39)$ & $20(7)$ & & $83(23)$ & $54(23)$ & \\
\hline Probably prefer surgery & $30(10)$ & $31(10)$ & & $51(14)$ & $10(4)$ & \\
\hline Definitely prefer surgery & $38(13)$ & $129(43)$ & & $162(44)$ & $5(2)$ & \\
\hline
\end{tabular}




\begin{tabular}{|c|c|c|c|c|c|c|}
\hline Characteristic & $\begin{array}{c}\text { Randomized } \\
\text { Cohort } \\
(\mathrm{N}=301)\end{array}$ & $\begin{array}{c}\text { Observational } \\
\text { Cohort } \\
(\mathrm{N}=300)\end{array}$ & $\begin{array}{c}P \\
\text { Value }\end{array}$ & $\begin{array}{l}\text { Surgical } \\
\text { Treatment } \\
(\mathrm{N}=368) \grave{\dagger}\end{array}$ & $\begin{array}{l}\text { Nonsurgical } \\
\text { Treatment } \\
(\mathrm{N}=233) \doteqdot\end{array}$ & $\begin{array}{c}P \\
\text { Value }\end{array}$ \\
\hline Pseudoclaudication - no. (\%) & $259(86)$ & $252(84)$ & 0.56 & $319(87)$ & $192(82)$ & 0.19 \\
\hline $\begin{array}{l}\text { Straight-leg-raising test or femoral-tension } \\
\text { sign — no. (\%) }\end{array}$ & $44(15)$ & $41(14)$ & 0.83 & $48(13)$ & $37(16)$ & 0.39 \\
\hline Dermatomal pain radiation — no. (\%) & $239(79)$ & $229(76)$ & 0.42 & $288(78)$ & $180(77)$ & 0.85 \\
\hline Any neurologic deficit — no. (\%) & $142(47)$ & $152(51)$ & 0.44 & $185(50)$ & $109(47)$ & 0.45 \\
\hline Asymmetric reflex depression & $53(18)$ & $40(13)$ & 0.18 & $65(18)$ & $28(12)$ & 0.08 \\
\hline Asymmetric sensory decrease & $79(26)$ & $90(30)$ & 0.35 & $108(29)$ & $61(26)$ & 0.45 \\
\hline Asymmetric motor weakness & $74(25)$ & $72(24)$ & 0.94 & $87(24)$ & $59(25)$ & 0.71 \\
\hline Listhesis level — no. (\%) & & & 0.17 & & & 0.69 \\
\hline L3-L4 & $34(11)$ & $23(8)$ & & $33(9)$ & $24(10)$ & \\
\hline L4-L5 & $267(89)$ & $277(92)$ & & $335(91)$ & $209(90)$ & \\
\hline \multicolumn{7}{|l|}{ Stenosis level — no. (\%) } \\
\hline L2-L3 & $31(10)$ & $22(7)$ & 0.26 & $33(9)$ & $20(9)$ & 0.99 \\
\hline L3-L4 & $136(45)$ & $100(33)$ & 0.004 & $145(39)$ & $91(39)$ & 1.00 \\
\hline L4-L5 & $285(95)$ & $295(98)$ & 0.03 & $357(97)$ & $223(96)$ & 0.54 \\
\hline L5-S1 & $27(9)$ & $30(10)$ & 0.77 & $29(8)$ & $28(12)$ & 0.12 \\
\hline $\begin{array}{l}\text { No. of moderate or severe stenotic levels - } \\
\text { no. (\%) }\end{array}$ & & & 0.10 & & & 0.14 \\
\hline 0 & $7(2)$ & $16(5)$ & & $9(2)$ & $14(6)$ & \\
\hline 1 & $179(59)$ & $191(64)$ & & $231(63)$ & $139(60)$ & \\
\hline 2 & $96(32)$ & $76(25)$ & & $104(28)$ & $68(29)$ & \\
\hline$\geq 3$ & $19(6)$ & $17(6)$ & & $24(7)$ & $12(5)$ & \\
\hline \multicolumn{7}{|l|}{ Stenosis location - no. (\%) } \\
\hline Central & $277(92)$ & $272(91)$ & 0.65 & $341(93)$ & $208(89)$ & 0.20 \\
\hline Lateral recess & $286(95)$ & $260(87)$ & $<0.001$ & $338(92)$ & $208(89)$ & 0.36 \\
\hline Neuroforamen & $123(41)$ & $120(40)$ & 0.89 & $152(41)$ & $91(39)$ & 0.64 \\
\hline Stenosis severity - no. (\%) & & & 0.08 & & & 0.08 \\
\hline Mild & $7(2)$ & $16(5)$ & & $9(2)$ & $14(6)$ & \\
\hline Moderate & $116(39)$ & $99(33)$ & & $131(36)$ & $84(36)$ & \\
\hline Severe & $178(59)$ & $185(62)$ & & $228(62)$ & $135(58)$ & \\
\hline Instability - no. (\%) ††' & $26(9)$ & $21(7)$ & 0.55 & $35(10)$ & $12(5)$ & 0.07 \\
\hline
\end{tabular}

* Plus-minus values are means \pm SD.

$\dagger$ Patients in the two cohorts combined were classified according to whether they received surgical treatment or only nonsurgical treatment during the first 2 years of enrollment.

$\mp$ Race or ethnic group was self-assessed. Whites and blacks could be either Hispanic or non-Hispanic.

$\int$ This category includes patients who were receiving or had applications pending for workers' compensation, Social Security compensation, or other compensation.

I The body-mass index is the weight in kilograms divided by the square of the height in meters.

| Other problems included those related to stroke, cancer, lung disease, fibromyalgia, chronic fatigue syndrome, posttraumatic stress disorder, alcohol abuse, drug dependency, liver disease, kidney disease, vascular disease, neurologic disease, migraine, or anxiety.

$* *$ The SF-36 scores range from 0 to 100 , with higher scores indicating less severe symptoms.

t个 The Oswestry Disability Index ranges from 0 to 100, with lower scores indicating less severe symptoms.

The Stenosis Frequency Index ranges from 0 to 24, with lower scores indicating less severe symptoms.

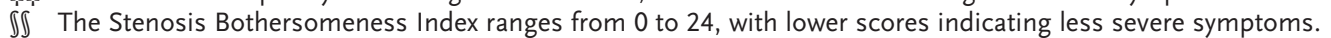

9 9 The Low Back Pain Bothersomeness Scale ranges from 0 to 6, with lower scores indicating less severe symptoms.

\|\| Data were not available for eight patients.

w⿰冫欠

$\uparrow \uparrow \uparrow$ Instability is defined as a change of more than 10 degrees of angulation or more than $4 \mathrm{~mm}$ of translation of the vertebrae between flexion and extension of the spine. 


\begin{tabular}{|c|c|c|c|}
\hline Variable & $\begin{array}{c}\text { Randomized } \\
\text { Cohort } \\
(\mathrm{N}=172)\end{array}$ & $\begin{array}{c}\text { Observational } \\
\text { Cohort } \\
(N=200)\end{array}$ & P Value \\
\hline Specific procedure - no. (\%) $\dagger$ & & & 0.92 \\
\hline Decompression only & $10(6)$ & $10(5)$ & \\
\hline Fusion without instrumentation & $35(21)$ & $43(21)$ & \\
\hline Fusion with instrumentation & $123(73)$ & $147(74)$ & \\
\hline Multilevel fusion — no. (\%) & $46(27)$ & $40(20)$ & 0.13 \\
\hline \multicolumn{4}{|l|}{ Decompression level — no. (\%) } \\
\hline L2-L3 & $25(15)$ & $17(8)$ & 0.08 \\
\hline L3-L4 & $92(54)$ & $84(42)$ & 0.02 \\
\hline L4-L5 & $165(98)$ & $190(95)$ & 0.34 \\
\hline L5-S1 & $60(36)$ & $47(24)$ & 0.01 \\
\hline No. of levels decompressed — no. of patients (\%) & & & 0.01 \\
\hline 0 & $1(1)$ & $2(1)$ & \\
\hline 1 & $56(33)$ & $98(49)$ & \\
\hline 2 & $65(38)$ & $65(32)$ & \\
\hline$\geq 3$ & $47(28)$ & $35(18)$ & \\
\hline Operation time $-\min$ & $210.5 \pm 81.7$ & $202.7 \pm 85.8$ & 0.37 \\
\hline Blood loss - $\mathrm{ml}$ & $570.0 \pm 425.7$ & $606.2 \pm 511.2$ & 0.47 \\
\hline \multicolumn{4}{|l|}{ Blood replacement — no. (\%) } \\
\hline Intraoperative replacement & $60(36)$ & $67(34)$ & 0.71 \\
\hline Postoperative transfusion & $27(16)$ & $51(26)$ & 0.04 \\
\hline Length of hospital stay — days & $6.9 \pm 28.7$ & $4.8 \pm 3.3$ & 0.30 \\
\hline \multicolumn{4}{|l|}{ Intraoperative complications - no. (\%)』 } \\
\hline Dural tear or cerebrospinal fluid leak & $19(11)$ & $18(9)$ & 0.59 \\
\hline Vascular injury & $1(1)$ & 0 & 0.93 \\
\hline Other & $3(2)$ & $6(3)$ & 0.67 \\
\hline
\end{tabular}

identical in the randomized and the observational cohorts. For SF-36 bodily pain, the effect was 17.8 ( $95 \%$ CI, 12.5 to 23.0 ) in the randomized cohort as compared with 18.5 (95\% CI, 13.4 to 23.6) in the observational cohort; for SF-36 physical function, the effect was 16.7 (95\% CI, 11.4 to 22.1) in the randomized cohort as compared with 19.9 (95\% CI, 14.8 to 24.9 ) in the observational cohort; and for the Oswestry Disability Index, the effect was -15.9 (95\% CI, -20.2 to -11.7$)$ in the randomized cohort as compared with -17.7 (95\% CI, -21.6 to -13.7 ) in the observational cohort. The global hypothesis test comparing the treatment effects in the randomized and the observational cohorts over all time periods revealed no significant difference between the cohorts: $\mathrm{P}=0.29$ for SF-36 bodily pain, $\mathrm{P}=0.28$ for SF-36 physical function, and $\mathrm{P}=0.97$ for the Oswestry Disability Index.

\section{SUBGROUP ANALYSES}

Models fitted for selected subgroups were examined for evidence of modification of treatment efficacy. Participants less than 65 years old at baseline had larger treatment effects in favor of surgery at 3 months (21.3 vs. 14.6 for bodily pain, $\mathrm{P}=0.02$ ) but not at 1 or 2 years. The treatment effect for a degenerative spondylolisthesis level of L3-L4 was larger than that for a level of L4-L5 (33.1 vs. 16.8 for SF-36 bodily pain, $\mathrm{P}=0.01$ ) at 2 years but not at 3 months or 1 year. Participants with no more than a high-school education had smaller treatment effects for surgery at 3 months (12.8 vs. 20.5 for SF-36 bodily pain, $\mathrm{P}=0.02$ ) and 2 years (11.5 vs. 21.6 for SF-36 bodily pain, $\mathrm{P}=0.01$ ). Other subgroups (defined according to sex, smoking history, severity of symptoms at baseline, duration of symptoms, treatment preference, 


\begin{tabular}{|c|c|c|c|}
\hline \multicolumn{4}{|l|}{ Table 2. (Continued.) } \\
\hline Variable & $\begin{array}{c}\text { Randomized } \\
\text { Cohort } \\
(\mathrm{N}=172)\end{array}$ & $\begin{array}{c}\text { Observational } \\
\text { Cohort } \\
(\mathrm{N}=\mathbf{2 0 0})\end{array}$ & P Value \\
\hline \multicolumn{4}{|l|}{ Postoperative complications and events - no. (\%) } \\
\hline Nerve-root injury & $1(1)$ & 0 & 0.93 \\
\hline Wound dehiscence & 0 & $1(1)$ & 0.93 \\
\hline Wound hematoma & 0 & $1(1)$ & 0.93 \\
\hline Wound infection & $8(5)$ & $3(2)$ & 0.12 \\
\hline Other & $21(12)$ & $14(7)$ & 0.10 \\
\hline Death within 3 mo after surgery - no. (\%) & $1(1)$ & $1(1)$ & 0.55 \\
\hline Additional spine surgeries within 1 yr - no. (\%) $\|$ *** & $13(8)$ & $11(6)$ & 0.40 \\
\hline Recurrent stenosis or progressive listhesis & $1(1)$ & $1(1)$ & \\
\hline Pseudarthrosis or fusion exploration & 0 & $1(1)$ & \\
\hline Complication & $11(6)$ & $7(4)$ & \\
\hline New condition & $1(1)$ & $1(0.5)$ & \\
\hline Additional spine surgeries within $2 \mathrm{yr}-$ no. (\%) $\|$ & $18(11)$ & $23(12)$ & 0.84 \\
\hline Recurrent stenosis or progressive listhesis & $5(3)$ & $5(2)$ & \\
\hline Pseudarthrosis or fusion exploration & 0 & $3(2)$ & \\
\hline Complication & $13(8)$ & $11(6)$ & \\
\hline New condition $\|$ & $1(1)$ & $4(2)$ & \\
\hline
\end{tabular}

* A total of 172 patients in the randomized cohort and 200 patients in the observational cohort underwent surgery within 2 years after enrollment. Information about the surgery was available for 169 patients from the randomized cohort and 200 from the observational cohort. Plus-minus values are means \pm SD.

$\dagger$ Data on specific procedures were available for 168 patients in the randomized cohort and 200 patients in the observational cohort.

† All 270 patients undergoing fusion with instrumentation had pedicle screws; 46 underwent additional interbody fusion.

$\int$ No cases were reported of aspiration into the respiratory tract, nerve-root injury, or operation at the wrong level.

I Complications or events occurring up to 8 weeks after surgery are listed. There were no reported cases of bone-graft complication, cerebrospinal fluid leak, paralysis, cauda equina injury, or pseudarthrosis.

|| The postsurgical reoperation rates are Kaplan-Meier estimates.

* $*$ One new stenosis occurred in the randomized cohort, and two new herniations and two new stenoses occurred in the observational cohort.

number of stenotic levels, severity of stenosis on imaging, number of coexisting conditions, and baseline SF-36 mental component summary score) did not show significant effect modification. These results should be considered cautiously, because the study was not designed or powered to examine subgroup differences.

\section{DISCUSSION}

In patients with image-confirmed degenerative spondylolisthesis and symptoms persisting for at least 12 weeks, the intention-to-treat analysis found no significant advantage for surgery over nonsurgical care, but the analysis was severely limited by treatment crossover. As-treated analyses showed that surgery was superior to nonsurgical treatment in relieving symptoms and im- proving function. This treatment effect was seen as early as at the 6-week follow-up and persisted over 2 years. The nonsurgical-treatment group showed only moderate improvement over time. The smaller treatment effect for surgery seen in less-educated subjects is intriguing but unexplained and may be a chance finding in a post hoc subgroup.

The randomized and observational cohorts were remarkably similar at baseline. The only significant differences were small ones in level and location of stenosis on baseline imaging. The cohorts also had similar outcomes, with no significant differences between the treatment effects in the as-treated analyses. These similarities support the validity of the combined analysis presented here.

There was little evidence of harm from either 


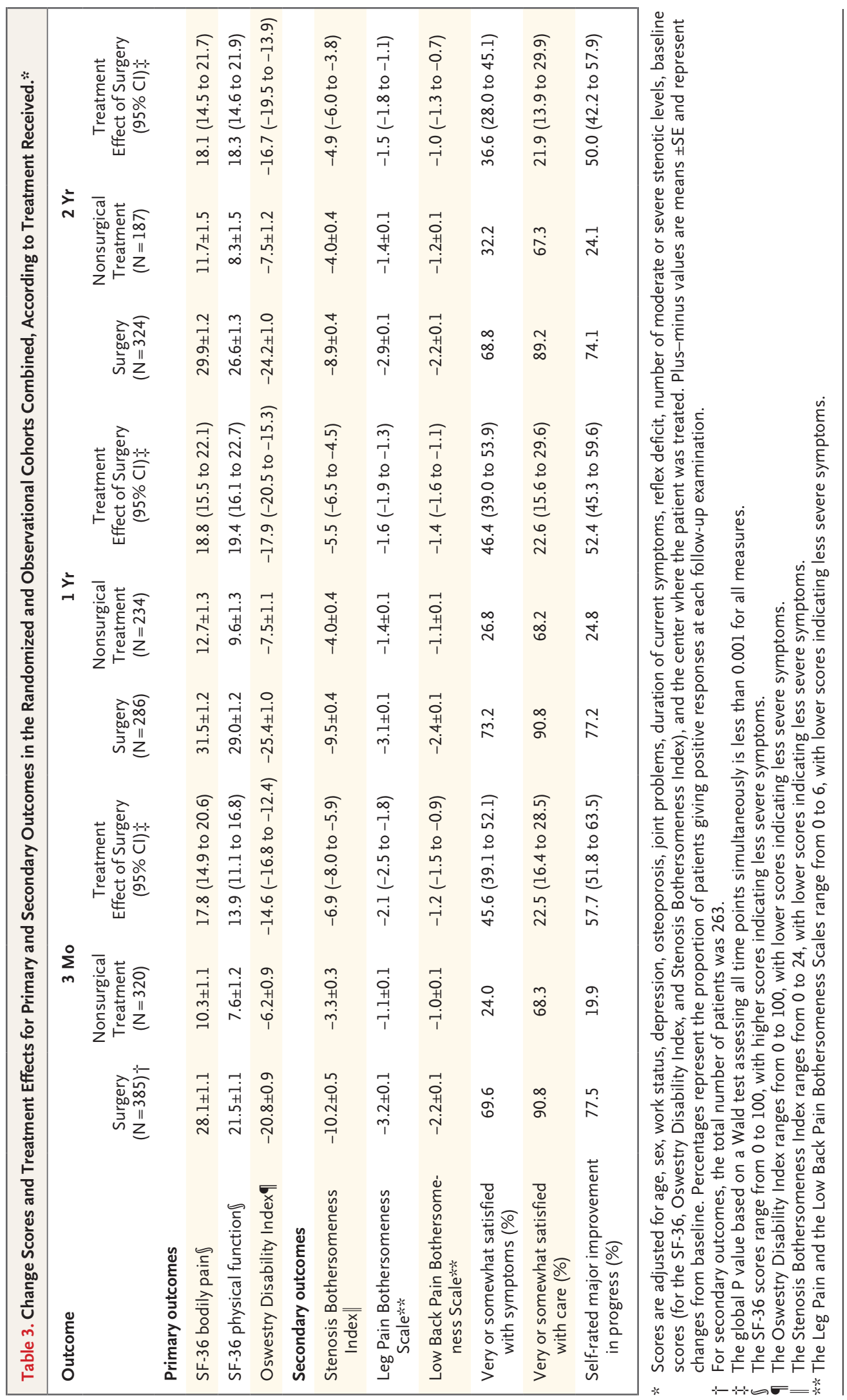


treatment. Often patients fear they will get worse without surgery, but the patients receiving nonsurgical treatment, on average, showed moderate improvement in all outcomes. No patients undergoing surgical or nonsurgical treatment had cauda equina syndrome; $89 \%$ of surgical patients had no operative complications.

The characteristics of the participants in the SPORT were similar to those in previous studies of degenerative spondylolisthesis and mixed cohorts of patients with stenosis. The mean age of 66 years was similar to that in the cohorts reported by Herkowitz and $\mathrm{Kurz}^{8}$ (63.5 years), Fischgrund et al.7 (67 years), the Maine Lumbar Spine Study (MLSS) ${ }^{3}$ (66 years), Yukawa et al. ${ }^{26}$ (63 years), and Malmivaara et al. ${ }^{5}$ (63 years). At enrollment, $60 \%$ of the SPORT participants reported having had symptoms for more than 6 months, as did $60 \%$ of the participants in the MLSS. Baseline functional status in the SPORT was similar to that in the MLSS (mean SF-36 physical function scores, 34 and 35, respectively) and in the randomized trial by Malmivaara et al. (mean Oswestry Disability Index scores, 41.5 and 35.0, respectively).

The surgical outcomes in the SPORT were generally similar to those in previous surgical series. Herkowitz and $\mathrm{Kurz}^{8}$ reported absolute improvements of 33\% for back pain and 55\% for leg pain (6-point scales) at 3 years, similar to the changes of $31 \%$ and $41 \%$, respectively (7-point scales), seen in the SPORT at 2 years. Also, the improvement at 1 year in the patients in the SPORT who were undergoing surgery for degenerative spondylolisthesis was similar to the outcomes of surgery in the MLSS mixed-stenosis (those with and those without degenerative spondylolisthesis) cohort. The improvement in the SF-36 bodily pain score was 32 in the SPORT and 43 in the MLSS, and the improvement in the SF-36 physical function score was 29 in the SPORT and 27 in the MLSS. ${ }^{3}$

The nonsurgical outcomes in the SPORT were similar to those in the study by Malmivaara et al. ${ }^{5}$ and in the MLSS. ${ }^{3}$ Malmivaara et al. reported absolute improvements in back pain at 2 years of $18 \%$ on an 11-point scale, as compared with $17 \%$ on a 7-point scale in the SPORT, and an improvement in leg pain of $16 \%$, as compared with $17 \%$ in the SPORT. Similarly, at 1 year the MLSS reported an improvement of 12.0 points in SF-36 bodily pain, as compared with 12.7 in the SPORT. The nonsurgical functional outcomes, however, were better in the SPORT than in these previous studies. SF-36 physical function improved by 9.6 points in the SPORT nonsurgical group, as compared with 1.0 point in the MLSS, and the Oswestry Disability Index improved by -7.5 points in the SPORT, as compared with -4.5 points in the study by Malmivaara et al. The somewhat greater improvement in the SPORT may be related to the nonsurgical treatments received. The SPORT participants had higher rates of epidural steroid injections than did the MLSS participants (44\% vs. $18 \%)$, similar rates of physical therapy, and much lower use of activity restriction (16\% vs. $29 \%$ ) and transcutaneous electrical nerve stimulation ( $2 \%$ vs. $14 \%$ ). Differences in nonsurgical outcomes might also be due to differences in the underlying disease process in patients with degenerative spondylolisthesis as compared with a mixed stenosis population in the study by Malmivaara et al. and in the MLSS.

We can directly compare estimates of treatment effect in the SPORT with those in the MLSS and the study by Malmivaara et al. The estimated 1-year treatment effects for surgery in the SPORT were smaller than those in the MLSS (18.8 vs. 30.4 points for SF-36 bodily pain, and 19.4 vs. 25.5 points for SF-36 physical function). However, the MLSS did not adjust treatment effects for baseline differences between the treatment groups, which probably explains these discrepancies. The estimated 1-year treatment effects were similar in the SPORT and in the study by Malmivaara et al. (Oswestry Disability Index, -17.9 vs. -11.3 , respectively; leg pain, 23\% [7-point scale] vs. $15 \%$ [11-point scale], respectively; and back pain, 20\% [7-point scale] vs. $21 \%$ [11-point scale], respectively.

The 1-year rate of reoperation for recurrent stenosis or spondylolisthesis was $0.6 \%$, less than the rates reported by Malmivaara et al. (2\%) and the MLSS $(1.2 \%)$. The reoperation rate increased to $3 \%$ at 2 years. The perioperative mortality rate was $0.6 \%$, which is less than the $1.3 \%$ seen in Medicare patients after fusion surgery for spondylolisthesis. ${ }^{27}$ The 2-year mortality rate was similar in both treatment groups and less than actuarial projections.

A limitation of this study is the marked degree of nonadherence to randomized treatment. The protocol stipulated that patients assigned to surgery have their surgery within 3 to 6 months after enrollment, a period thought to be appro- 


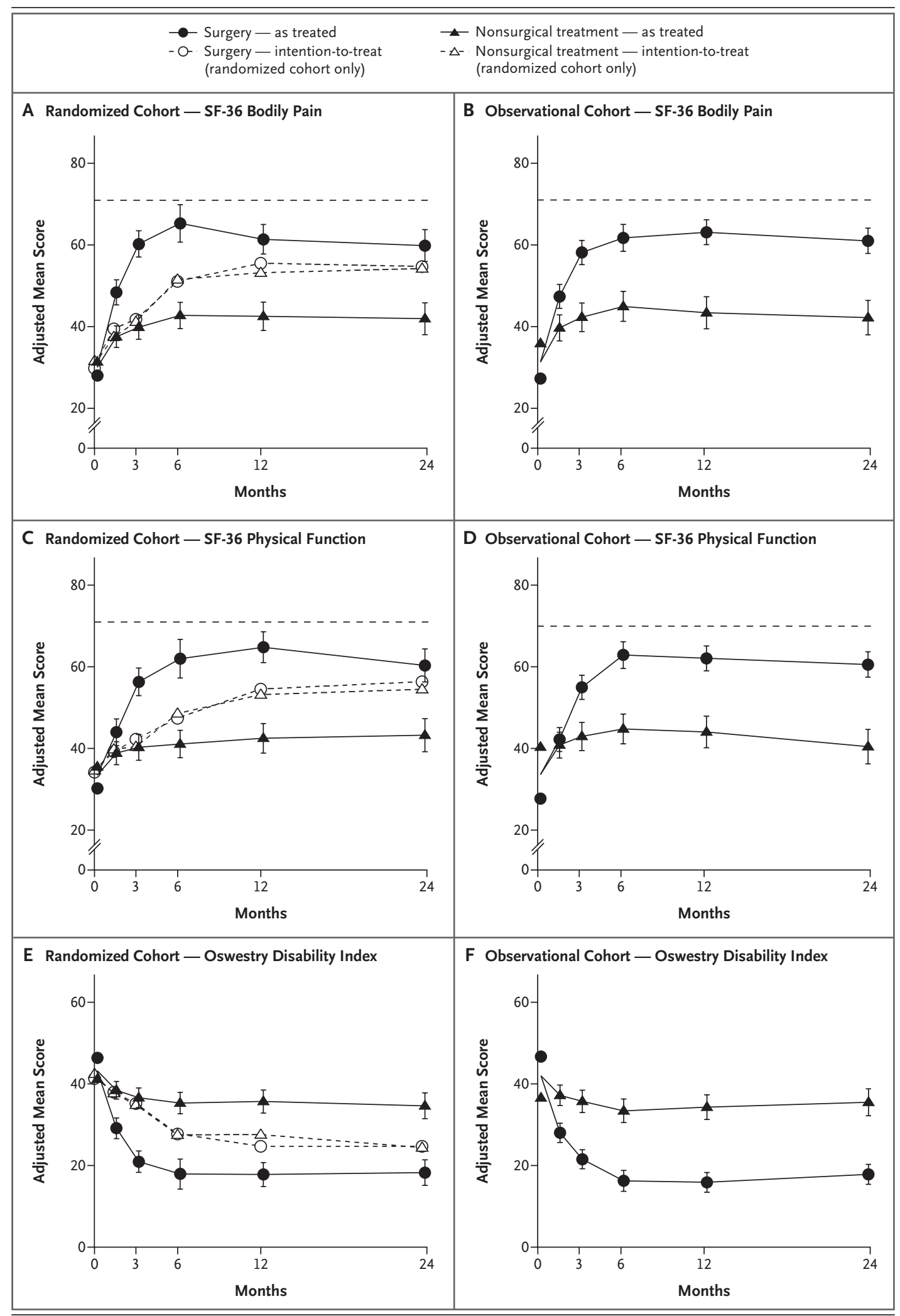


Figure 2 (facing page). Intention-to-Treat and As-Treated Results over Time for the Primary Outcome Measures of SF-36 Bodily Pain (Panels A and B), SF-36 Physical Function (Panels $C$ and D), and the Oswestry Disability Index (Panels E and F).

SF-36 bodily pain and physical function scores range from 0 to 100, with higher scores indicating less severe symptoms. The Oswestry Disability Index ranges from 0 to 100 , with lower scores indicating less severe symptoms. The horizontal dashed line in each of the four SF-36 graphs represents the age- and sex-adjusted norms. I bars represent the $95 \%$ confidence intervals. The floating symbols at 0 months represent the observed mean scores for each treatment group, whereas the plotline at 0 months originates from the overall mean as used in the adjusted analyses.

priate in the clinical experience of the investigators. Although patients consented to this proto$\mathrm{col}$, as in all clinical trials this consent could be changed at the request of the patient, and many chose to do so. This reduced the power of the intention-to-treat analysis to demonstrate a treatment effect. Although the as-treated analysis lost the strong protection from confounding conferred by randomization, these analyses were carefully controlled for important covariates and yielded results similar to previous studies.

Another limitation is the heterogeneity of the treatment interventions. The choice of nonsurgical therapies was at the discretion of the treating physician and the patient. However, with limited evidence regarding efficacy for most nonsurgical treatments for degenerative spondylolisthesis, creating a fixed protocol for nonsurgical treatment was neither clinically feasible nor generalizable. The nonsurgical treatments used were consistent with published guidelines. ${ }^{28,29}$ Similarly, the surgeries performed varied in terms of the presence, method, and extent of spinal fusion accompanying the decompression. We cannot make direct conclusions regarding the comparison between the effect of surgery and any specific nonsurgical treatment, nor do we directly compare the efficacy of nonsurgical treatment with one specific surgical technique.

The magnitudes of the mean changes reported here after surgery for degenerative spondylolisthesis are less than those reported for patients in a SPORT observational cohort undergoing surgery for intervertebral disk herniation. The mean change scores after 2 years were as follows: SF-36 bodily pain, 29.9 for degenerative spondylolisthesis versus 42.6 for intervertebral disk herniation; SF-36 physical function, 26.7 for degenerative spondylolisthesis versus 43.9 for intervertebral disk herniation; Oswestry Disability Index, -24.2 for degenerative spondylolisthesis versus 37.6 for intervertebral disk herniation. ${ }^{9,10}$ However, the treatment effects for surgery in the degenerativespondylolisthesis group were larger than those in the study of intervertebral disk herniation (18.4 for bodily pain in the degenerative-spondylolisthesis group vs. 10.2 in the intervertebral-disk-herniation study) because of dramatic improvements in the nonsurgical group with intervertebral disk herniation not seen in the degenerative-spondylolisthesis group.

In these nonrandomized comparisons with careful control of potentially confounding baseline factors, patients with persistent neurogenic claudication from degenerative spondylolisthesis treated surgically showed substantially greater improvement in pain and function, as well as satisfaction, for 2 years. Characteristics of the patients and treatment outcomes were similar in the randomized and observational cohorts.

Supported by a grant (U01-AR45444-01A1) from the National Institute of Arthritis and Musculoskeletal and Skin Diseases (NIAMS) and the Office of Research on Women's Health; by the National Institutes of Health; by the National Institute of Occupational Safety and Health and the Centers for Disease Control and Prevention; and by a grant (P60-AR048094-01A1 to the Multidisciplinary Clinical Research Center in Musculoskeletal Diseases) and a Research Career Award (1 K23 AR 048138-01 to Dr. Lurie) from NIAMS. These sources had no role in the design or conduct of the study; in the collection, management, analysis, or interpretation of the data; or in the preparation, review, or approval of the manuscript.

Dr. Weinstein reports receiving consulting fees from United Healthcare and an honorarium as editor-in-chief of Spine. Dr. Lurie reports receiving consulting fees from the Pacific Business Group on Health. Dr. Birkmeyer reports receiving grant support from Blue Cross/Blue Shield of Michigan. Dr. Herkowitz reports receiving consulting fees and royalties from Medtronic Sofamor Danek. Dr. Cammisa reports owning equity in HealthPoint Capital Partners, K2M, Mazor Surgical Technologies, and Spinal Kinetics. Dr. Albert reports receiving consulting fees, lecture fees, and royalties from DePuy Spine and owning equity in K2M. Dr. Emery reports receiving departmental block grant support from Zimmer, Medtronic Sofamor Danek, and Synthes. Dr. Lenke reports receiving consulting fees and grant support from Medtronic Sofamor Danek and Biotek. Dr. Longley reports owning equity in Custom Spine. Dr. Errico reports receiving consulting fees from Stryker and Fastenetix; fellowship support from AOSpine, DePuy Spine, and Medtronic Sofamor Danek; and clinical research grant support from Stryker and Synthes. No other potential conflict of interest relevant to this article was reported.

We thank Tamara S. Morgan, Department of Orthopaedic Surgery, Dartmouth Medical School, for graphic design and production and for overall assistance to the SPORT. 


\section{APPENDIX}

In addition to the authors, the following investigators participated in the Spine Patient Outcomes Research Trial (institutions are in order from highest to lowest enrollment): Dartmouth Medical School, Hanover, NH - J. Forman, B. Butler-Schmidt, J.J. Hebb, P. Bernini. R. Hazard, P. Ball, C. Murray, M. Splaine, D. Sengupta, H. Schmidek, R. Rose, C. Olson, P. McDonough, H. Magnasdottir; William Beaumont Hospital, Royal Oak, MI - G. Bradley, M. Lurie, L. Kurz, J. Fischgrund, D. Montgomery, E. Truumees; Rothman Institute at Thomas Jefferson Hospital, Philadelphia - C. Simon, T. Conliffe; Hospital for Special Surgery, New York — B. Green, J. Farmer, H. Sandhu; Nebraska Foundation for Spinal Research, Omaha - N. Fullmer, A.M. Fredericks, R. Woodward, J. Fuller, E. Phillips, J. McClellan, P. Bowman, T. Burd; Emory University-Emory Clinic, Atlanta - S. Boden, S. Lashley, H. Levy, D. Hubbell, M. Schaufele, J. Rhee, S.T. Yoon, S. Dreyer, J. Heller; Washington University, St. Louis - G. Stobbs, K. Bridwell, A. Margherita, K.D. Riew, B. Taylor, J. Metzler; University Hospitals of Cleveland and Case Western Reserve University, Cleveland - C. Furey, K. Higgins, J.X. Yoo, E.B. Marsolais, H. Bohlman; Hospital for Joint Diseases, New York - A. Lee, J. Bendo, J. Goldstein, J. Spivak, R. Perry, R. Schoenfeldt, R. Moskovich, J. Dryer; Kaiser Permanente, Oakland, CA - H. Goldberg, P. Malone, F. Massimino; University ofCalifornia, San Francisco, San Francisco - P. Malone, S. Berven, T. Smith; Rush-Presbyterian-St. Luke's Medical Center, Chicago - G. Andersson, H. An, M. Hickey, E. Goldberg, F. Philips; Maine Spine and Rehabilitation, Scarborough — R. Keller, L. Thibodeau, J. Florman.

\section{REFERENCES}

1. Jacobsen S, Sonne-Holm S, Rovsing H, Monrad H, Gebuhr P. Degenerative lumbar spondylolisthesis: an epidemiological perspective: the Copenhagen Osteoarthritis Study. Spine 2007;32:120-5.

2. Boden SD, Davis DO, Dina TS, Patronas NJ, Wiesel S. Abnormal magneticresonance scans of the lumbar spine in asymptomatic subjects: a prospective investigation. J Bone Joint Surg Am 1990; 72:403-8.

3. Atlas SJ, Deyo RA, Keller RB, et al. The Maine Lumbar Spine Study, Part III: 1-year outcomes of surgical and nonsurgical management of lumbar spinal stenosis. Spine 1996;21:1787-94.

4. Atlas SJ, Keller RB, Robson D, Deyo RA, Singer DE. Surgical and nonsurgical management of lumbar spinal stenosis: four-year outcomes from the Maine Lumbar Spine Study. Spine 2000;25:556-62. 5. Malmivaara A, Slatis P, Heliovaara M, et al. Surgical or nonoperative treatment for lumbar spinal stenosis? A randomized controlled trial. Spine 2007;32:1-8.

6. Bridwell KH, Sedgewick TA, O'Brien MF, Lenke LG, Baldus C. The role of fusion and instrumentation in the treatment of degenerative spondylolisthesis with spinal stenosis. J Spinal Disord 1993;6:46172.

7. Fischgrund JS, Mackay M, Herkowitz HN, Brower R, Montgomery DM, Kurz LT. Degenerative lumbar spondylolisthesis with spinal stenosis: a prospective, randomized study comparing decompressive laminectomy and arthrodesis with and without spinal instrumentation. Spine 1997;22:2807-12.

8. Herkowitz HN, Kurz LT. Degenerative lumbar spondylolisthesis with spinal stenosis: a prospective study comparing decompression with decompression and intertransverse process arthrodesis. J Bone Joint Surg Am 1991;73:802-8.

9. Weinstein JN, Lurie JD, Tosteson TD, et al. Surgical vs nonoperative treatment for lumbar disk herniation: the Spine Patient Outcomes Research Trial (SPORT) observational cohort. JAMA 2006;296: 2451-9.

10. Weinstein JN, Tosteson TD, Lurie JD, et al. Surgical vs nonoperative treatmen for lumbar disk herniation: the Spine Patient Outcomes Research Trial (SPORT) a randomized trial. JAMA 2006;296:244150.

11. Birkmeyer NJ, Weinstein JN, Tosteson AN, et al. Design of the Spine Patien Outcomes Research Trial (SPORT). Spine 2002;27:1361-72.

12. Tunis SR, Stryer DB, Clancy CM. Practical clinical trials: increasing the value of clinical research for decision making in clinical and health policy. JAMA 2003;290: 1624-32.

13. Cummins J, Lurie JD, Tosteson TD, et al. Descriptive epidemiology and prior healthcare utilization of patients in the Spine Patient Outcomes Research Trial's (SPORT) three observational cohorts: disc herniation, spinal stenosis, and degenerative spondylolisthesis. Spine 2006; 31:806-14.

14. Phelan EA, Deyo RA, Cherkin DC, et al. Helping patients decide about back surgery: a randomized trial of an interactive video program. Spine 2001;26:206-11. 15. Weinstein JN. Partnership: doctor and patient: advocacy for informed choice vs. informed consent. Spine 2005;30:269-72. 16. McHorney CA, Ware JE Jr, Lu JF, Sher bourne CD. The MOS 36-item Short-Form Health Survey (SF-36): III. Tests of data quality, scaling assumptions, and reliability across diverse patient groups. Med Care 1994;32:40-66.

17. Stewart AL, Greenfield S, Hays RD, et al. Functional status and well-being of patients with chronic conditions: results from the Medical Outcomes Study. JAMA 1989;262:907-13. [Erratum, JAMA 1989; 262:2542.]

18. Ware JE Jr, Sherbourne CD. The MOS 36-item Short-Form Health Survey. I. Conceptual framework and item selection. Med Care 1992;30:473-83.

19. Ware JE Jr, Snow KK, Kosinski M,
Gandek B. SF-36 Health Survey: manual and interpretation guide. Boston: Nimrod Press, 1993.

20. Daltroy LH, Cats-Baril WL, Katz JN, Fossel AH, Liang MH. The North American Spine Society lumbar spine outcome assessment instrument: reliability and validity tests. Spine 1996;21:741-9.

21. Deyo RA, Diehl AK. Patient satisfaction with medical care for low-back pain. Spine 1986;11:28-30.

22. Atlas SJ, Deyo RA, Patrick DL, Convery K, Keller RB, Singer DE. The Quebec Task Force classification for spinal disorders and the severity, treatment, and outcomes of sciatica and lumbar spinal stenosis. Spine 1996;21:2885-92.

23. Patrick DL, Deyo RA, Atlas SJ, Singer DE, Chapin A, Keller RB. Assessing health-related quality of life in patients with sciatica. Spine 1995;20:1899-908.

24. Fitzmaurice G, Laird NM, Ware JH. Applied longitudinal analysis. New York: Wiley, 2004.

25. Morgan FP, King T. Primary instability of lumbar vertebrae as a common cause of low back pain. J Bone Joint Surg Br 1957;39:6-22

26. Yukawa Y, Lenke LG, Tenhula J, Bridwell KH, Riew KD, Blanke K. A comprehensive study of patients with surgically treated lumbar spinal stenosis with neurogenic claudication. J Bone Joint Surg Am 2002;84:1954-9.

27. Deyo RA, Ciol MA, Cherkin DC, Loeser JD, Bigos SJ. Lumbar spinal fusion: a cohort study of complications, reoperations, and resource use in the Medicare population. Spine 1993;18:1463-70.

28. Acute low back problems in adults: assessment and treatment. Bethesda, MD: Department of Health and Human Services, 1994. (AHCPR publication no. 95-0643.) 29. Degenerative spondylolisthesis. In: North American Spine Society phase III clinical guidelines for multidisciplinary spine care specialists. LaGrange, IL: North American Spine Society; 2000.

Copyright (c) 2007 Massachusetts Medical Society. 